\title{
PURPOSE IN LIFE DURING COVID-19 CONFINEMENT: EFFECT OF PHYSICAL ACTIVITY AND MEDITATION
}

\author{
NÉSTOR ROMERO-RAMOS1, ÓSCAR ROMERO-RAMOS1, ARNOLDO JOSÉ GONZÁLEZ SUAREZ² \\ 'Universidad de Málaga, Málaga, Spain \\ ${ }^{2}$ Quality Leadership University, Ciudad de Panamá, Panamá
}

\author{
Mailing address: Óscar Romero-Ramos, Universidad de Málaga, 2 Av. de Cervantes, 29016 Málaga, Spain, \\ e-mail: oromero@uma.es
}

\begin{abstract}
Introduction. The pandemic caused by the COVID-19 virus has led states to issue orders for confinement and suspension of activities such as education. The purpose of this study is to interpret the Purpose in Life Test (PIL) and its relationship to physical activity and mental relaxation/meditation in confinement. Material and methods. A survey was conducted in an online form on 533 individuals (39 \pm 11 years) using the Purpose in Life Test (PIL) and an ad-hoc questionnaire regarding physical activity time (PA), mental relaxation/meditation time (RM), hours of sleep (HS), number of people in confinement (NPC) and concerns and satisfaction during confinement. Results. The overall mean of the PIL test was $114 \pm 16$, indicating a strong life purpose, and there were no differences by sex or by levels of physical activity, but for RM and age levels. The scores of the PIL test were positively correlated with the age, PA and time of RM. On the other hand, the main concern is the economy (50\%) and health or getting sick by COVID-19 (37\%), and what gives the greatest satisfaction is the family (40\%) and sharing and spending time with the family (33\%). People who perform RM activities at least $30 \mathrm{~min} /$ week have significantly higher PIL test scores. Conclusions. Despite the drastic changes caused by confinement, individuals have a strong life purpose. Family companionship, home PA and $\mathrm{RM}$ act as a protective factor during confinement and in maintaining physical and mental health.
\end{abstract}

Key words: physical health, relaxation, happiness, stress, sense of life

\section{Introduction}

The most prominent event of 2020 was undoubtedly the COVID-19 pandemic, whose epicenter was in Wuhan province in China, but is now spread worldwide [1]. The disease generates flu-like symptoms, but in addition, fever-associated anosmia and ageusia $\left(>37.5^{\circ} \mathrm{C}\right)$ appear as initial symptoms [2]. However, the respiratory difficulties it causes later can lead to death. On March 9, the first confirmed case of COVID-19 infection by the Ministry of Health of Panama [3] was reported, and the first death due to the disease was also confirmed [4]. On March 11, the World Health Organization declared a pandemic of the disease caused by the new coronavirus through its director, Tedros Adhanom [5, 1]. At that time, the Panamanian authorities began to take measures to alleviate the slope of the disease, suspending, inter alia, educational activities at all public and private levels, suspending agglomerations of acts involving the agglomeration of persons and establishing physical distancing and confinement at home.

This situation has had a strong immediate social and economic impact, the consequences of which are being assessed as the pandemic progresses, and part of this effort is the present research. The uncertainty generated by the pandemic and its management, as well as confinement, is having effects on people's mental health, increasing levels of stress, anxiety, and sleep disorders, as reported [6, 7]. Social distancing, self-isolation and travel restrictions have led to a reduction in the labor force in all economic sectors and have resulted in the loss of many jobs [8]. Economic uncertainty, the risk of disease contagion and the possibility of access to basic goods, as well as hospital services if necessary, can generate distress in the population that must be served, as part of a comprehensive program for the care of the population, to prevent health problems related to confinement.
Regular PA has many health benefits for humans, protecting bone, cardiovascular and neuromuscular systems, and decreasing the likelihood of neurodegenerative diseases such as Alzheimer's disease [9]. In addition, PA contributes to the mental well-being of people by reducing stress, anxiety and depression $[10,11]$, so it is highly advisable in situations that cause a lot of stress, such as the current situation of confinement due to the COVID-19 pandemic and the general uncertainty it has generated.

Relaxation and meditation techniques can also be very useful for stress management [12, 13]. Various studies have shown that meditation and mental relaxation techniques lead to a decrease in the general state of anxiety and develop qualities such as inner peace, satisfaction and creativity, compared to people who do not carry out these activities [13, 14]. Mindfulness could also be a powerful tool to transform the way we respond to life events and prevent the affective disorders that caused them [12]. Yanyu et al. [15] have proposed meditation as a tool to address stress generated by the COVID-19 pandemic. For this reason, the purpose of this research is to contribute to the study of the impact of the COVID-19 pandemic containment on the meaning of life in Panamanian society and to propose PA and RM as a strategy to cope with this situation, which ultimately comes out of the control of the person, and which can provide a way to at least take control of what he/she does.

\section{Material and methods}

The study included a total of 533 people living in different areas of Panama, aged between 18 and 77 years (39 years \pm 11 years), of whom 321 were women $(60 \%)$ and 212 were men $(40 \%)$. This group of people was selected randomly from the set of contact data available from people who attended the Quality Leadership University (QLU) for the purpose of conducting 
undergraduate and postgraduate training courses. The purpose in life test (PIL) developed by Crumbaugh and Macholick [16] and validated for Crumbaugh [17] was used. It was applied in its Spanish version, translated and validated by Noblejas de la Flor [18].The test consists of 20 items, with a Likert scale with values between 1 and 7 , with answers limited to statements that decant the response of the approach. For example, the statement in item 1 of the test "I usually find myself" corresponds at one end to the value 1 with "completely boring" and at the other end, the value 7 corresponds to "very excited", while the mean value of 4 points corresponds to indecision. The test was applied in a self-administered manner due to the quarantine situation to which the population was subjected, motivated by the COVID-19 pandemic, and was sent by e-mail to the participants, who, in a previous consultation, expressed their wish to reply to the above questionnaire. In addition to the PIL test, an ad hoc questionnaire was designed regarding the level of PA (min/ week) and RM (min/week), as well as hours of sleep (HS), number of people living together in confinement (NPC), days in confinement (DC) and filiations. Two open-ended questions were also asked (only half of the respondents were sent these questions), addressing concerns and what made people happiest during confinement: 1) What are you worried about right now? and 2) What makes you happy right now? With these questions we wanted to collect the main motivations, concerns and satisfactions of the respondents who are in a situation of quarantine. For the analysis of this section, the responses to the open-ended questions obtained were coded according to the categories obtained from the participants' responses. The category responses were then summed and the respective percentages were calculated for further interpretation [19].

\section{Statistical analysis}

The reliability of the instrument was determined by calculating Cronbach's $\alpha$ [19] Average values and standard deviations of all numerical results were calculated. The normality test was carried out to verify the distributions of the data, to execute the respective hypothesis tests and for all post hoc tests the Bonferroni correction was taken into account. The correlation between the numerical variables was evaluated using Spearman's correlation coefficient. Unless otherwise indicated, the significance level used in all tests was 0.05 .

\section{Results}

The general average age of the respondents was $39 \pm 11$ years, the average age of men being significantly higher than that of women (Tab. 1). The level of physical activity reported by $48 \%$ of the respondents (Fig. 1) was at most $30 \mathrm{~min}$, which is below the 150 min of weekly physical activity of medium intensity recommended by the World Health Organization to obtain the benefits of physical activity on health [20]. The weekly mental relaxation/meditation time reported by $57 \%$ of respondents was 10 minutes at most (Fig. 1), far removed from the time spent in some therapeutic procedures based on meditation for the treatment of stress and pain [21]. The average hours of sleep was 7 hours, a value that is within the minimum recommended by sleep experts in adults to have a good night's sleep [22, 23] (Tab. 1).

The general mean value for the sum of the test items (113 \pm 16 ) and the median value (117) is within the values obtained in other works $[24,25,26]$, as will be seen below. According to the values obtained from the PIL test, $60 \%$ of those surveyed have a clear sense of life, while $9 \%$ have a lack of life purpose or
Table l. Average and median weekly physical activity (PA) and mental relaxation/meditation (RM) values, nighttime sleep hours (HS), and PIL test values

\begin{tabular}{|c|c|c|c|c|c|}
\hline & Men & Women & $\boldsymbol{p}$ & General & $\mathrm{x}$ \\
\hline Age & $41 \pm 12$ & $38 \pm 11$ & 0.0006 & $39 \pm 11$ & 38 \\
\hline PA & $101 \pm 130$ & $86 \pm 117$ & 0.4430 & $92 \pm 122$ & 40 \\
\hline RM & $51 \pm 128$ & $57 \pm 126$ & 0.1015 & $55 \pm 186$ & 5 \\
\hline HS & $7 \pm 1$ & $7 \pm 2$ & 0.9647 & $7 \pm 1$ & 7 \\
\hline PIL & $114 \pm 16$ & $113 \pm 16$ & 0.1958 & $113 \pm 16$ & 117 \\
\hline
\end{tabular}

Average values \pm standard deviation. The p values are shown to contrast the equality hypothesis test for men and women of the mean values of: age in years; PA - physical activity in minutes per week; RM - mental relaxation/meditation in min/week; HS - hours of sleep; PIL - test scores; $\mathrm{x}$ - median. The number of respondents $\mathrm{n}=533$.

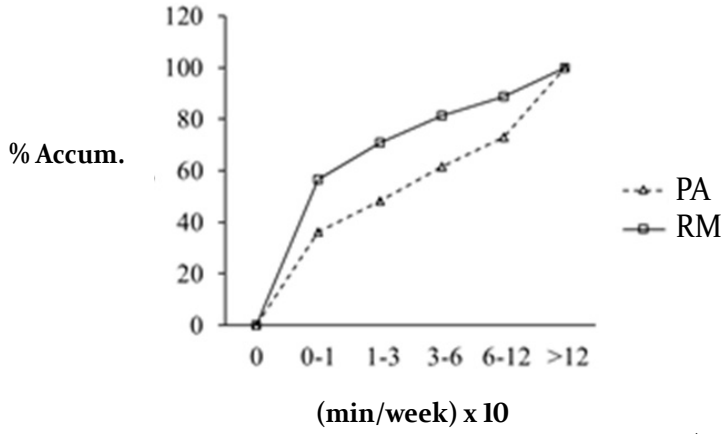

Figure 1. Cumulative percentage of weekly PA and RM (in minutes) by respondents.

existential emptiness; likewise, the behavior of the PIL test in this classification is identical between men and women (Fig. 2).

According to the correlation analysis carried out, age is positively and significantly correlated $(\mathrm{p}<0.05)$ with meditation time and the PIL test values (Tab. 2). The PIL test scores are positively and significantly correlated $(\mathrm{p}<0.05)$ with age, DC, PA and RM. Figure 3 shows mean charts comparing the PIL test values with respect to days of confinement, age in years, PA and RM. The Kruskal-Wallis test performed on each data set indicated the existence of statistically significant differences for age $(\mathrm{H}=28.0568, \mathrm{p}<0.0001)$ and $\mathrm{RM}(\mathrm{H}=22.398, \mathrm{p}=0.0003)$, but no differences were found for $\mathrm{DC}(\mathrm{H}=5.426, \mathrm{p}=0.246)$ and $\mathrm{PA}(\mathrm{H}=8.842, \mathrm{p}=0.0652)$. In the case of ages, the age group

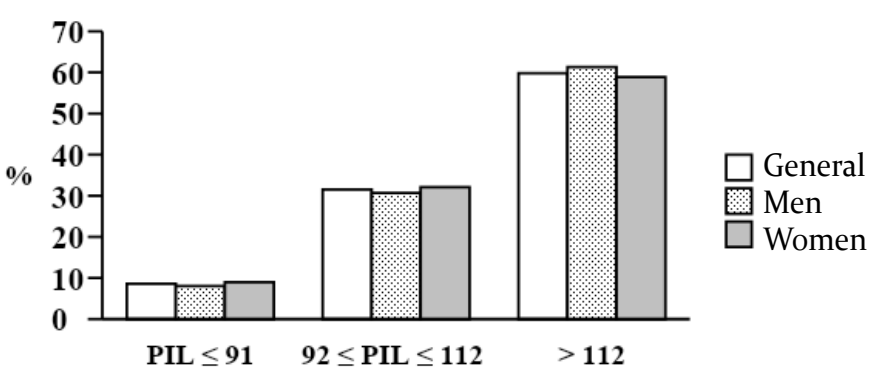

Figure 2. Percentage distribution of respondents in relation to the values of the PIL test, in general and by sex (PIL $\leq$ 91, lack of meaning in life; $92 \leq \mathrm{PIL} \leq 112$, zone of uncertainty; > 112, presence of meaning in life). 

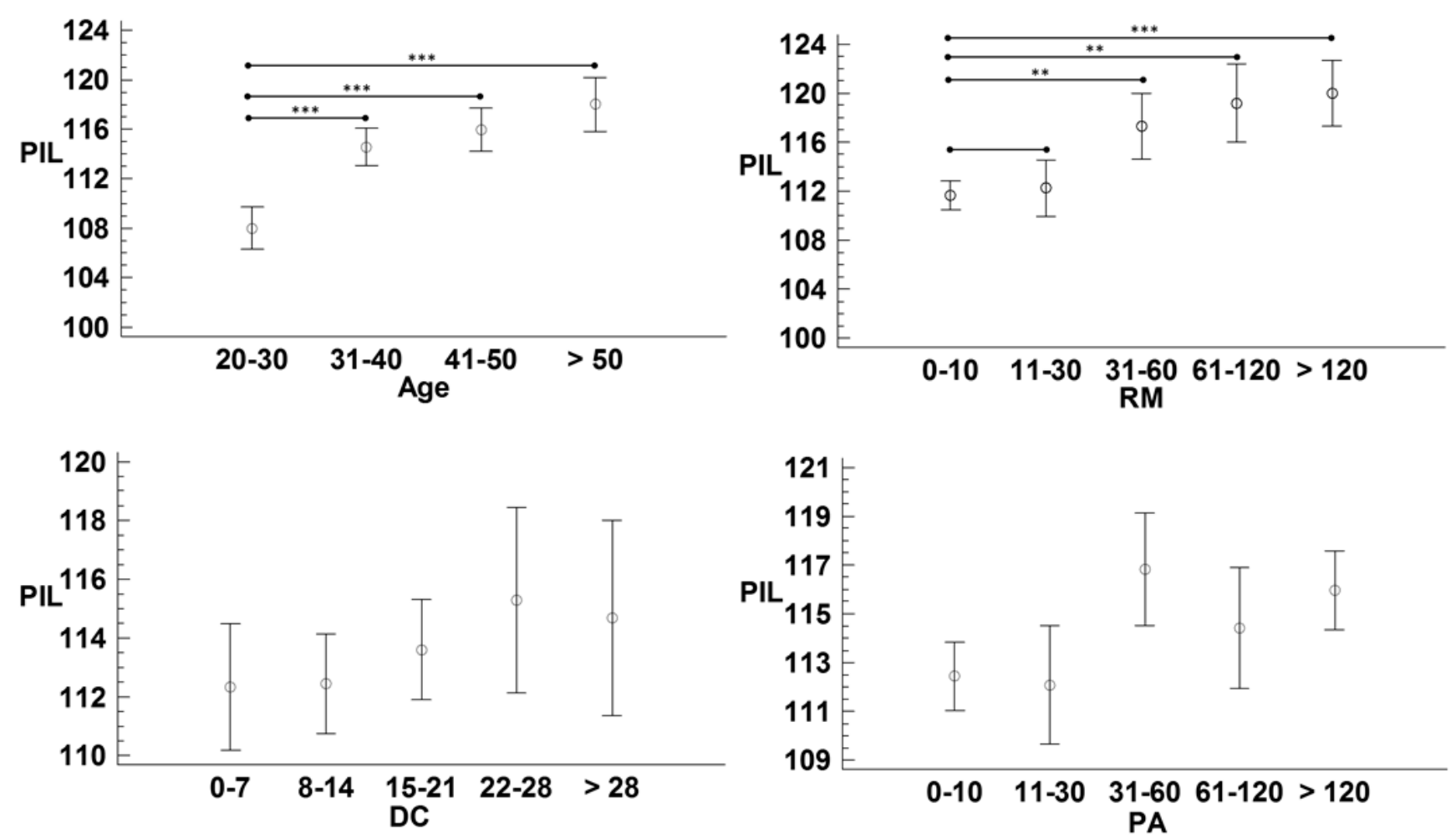

Figure 2. Mean charts of the PIL test with respect to DC - days of confinement, PA - physical activity, in min/week, RM - mental relaxation/ meditation, in min/week) and age of the participants (vertical lines represent the $95 \%$ confidence interval; ${ }^{* *}-\mathrm{p}<0.01 ;{ }^{* *}-\mathrm{p}<0.001$ ).

Table 2. Correlation analysis using Spearman's correlation coefficient $(\rho)$.

\begin{tabular}{|c|c|c|c|c|c|c|c|}
\hline & & DC & PA & RM & HS & NPC & PIL \\
\hline Age & $\rho$ & 0.009 & 0.0183 & 0.0981 & -0.1178 & 0.0723 & 0.2161 \\
\hline & $p$ & 0.8352 & 0.6743 & $\mathbf{0 . 0 2 4}$ & 0.082 & 0.2866 & $\mathbf{0 . 0 0 0 0}$ \\
\hline DC & $\rho$ & & 0.0138 & 0.0501 & -0.0312 & 0.0114 & 0.0862 \\
\hline & $p$ & & 0.7509 & 0.2496 & 0.6452 & 0.8667 & $\mathbf{0 . 0 4 6 8}$ \\
\hline PA & $\rho$ & & & 0.3271 & 0.0609 & -0.0252 & 0.1008 \\
\hline & $p$ & & & $\mathbf{0 . 0 0 0 0}$ & 0.3684 & 0.7107 & $\mathbf{0 . 0 2 0 3}$ \\
\hline RM & $\rho$ & & & & 0.0264 & -0.008 & 0.1897 \\
\hline & $p$ & & & & 0.6963 & 0.9065 & $\mathbf{0 . 0 0 0 0}$ \\
\hline HS & $\rho$ & & & & & -0.0462 & 0.1333 \\
\hline & $p$ & & & & & 0.4964 & 0.0491 \\
\hline NPC & $\rho$ & & & & & & 0.048 \\
\hline & $p$ & & & & & & 0.4794 \\
\hline
\end{tabular}

The values of the correlation coefficient $(\rho)$ and the probability $(\mathrm{p})$ are expressed. DC days of confinement; PA - physical activity in minutes per week; MR - mental relaxation/ meditation in minutes per week; HS - hours of sleep during quarantine; NPC - number of people in confinement.

of 20-30 years has the lowest average value of the PIL test (108 \pm 17 ) and in the case of RM, those who carry out this type of activities for $30 \mathrm{~min}$ or less, have average PIL values lower than or equal to 112, while those who practice RM activities for more than $30 \mathrm{~min} /$ week have average PIL test values above 117.

The quantitative analysis of the open questions is shown in Figure 4 and Figure 5. In this sense, what most worries Panamanian citizens surveyed is the economy (employment, debt, money, unemployment), followed by health (possibility of get-

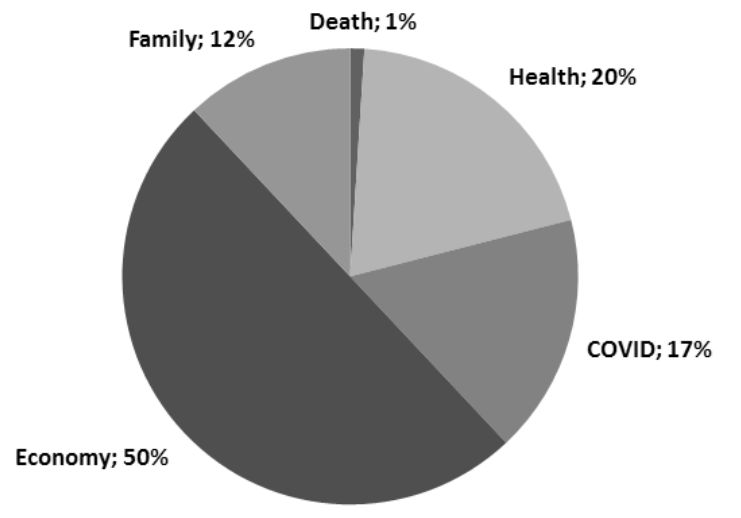

Figure 4. Categories extracted from the respondents' responses to the question: What are you worried about right now?

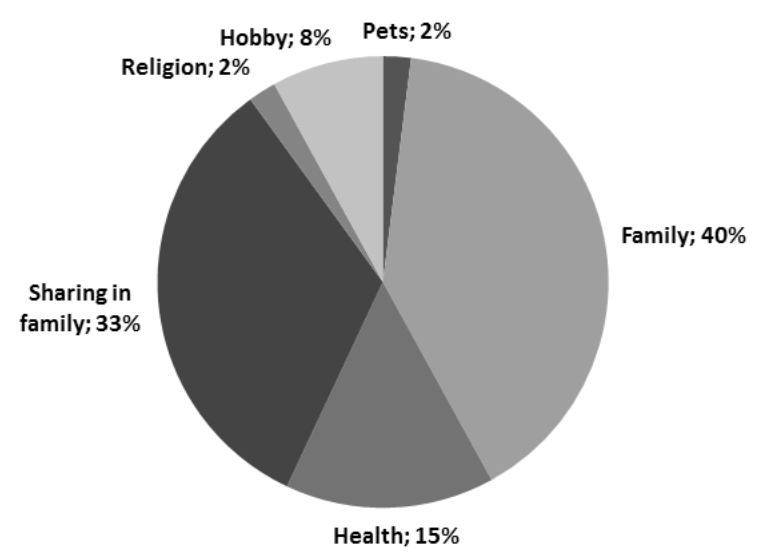

Figure 4. Categories taken from the respondents' responses to the question: What makes you happy right now? 
ting sick) and the concern of contracting COVID-19 (Fig. 4). On the other hand, what mostly brings happiness to those surveyed during the quarantine is family and the possibility of sharing time with loved ones; likewise, they stand out to be calm because of their health (Fig. 5). The NPC is $4 \pm 2$, and at least $10 \%$ of those surveyed are not alone. According to parentage, 32\% reported living with their partner, $26 \%$ with children, $17 \%$ with parents, $11 \%$ with siblings, $15 \%$ with other types of connection (friends, roommates, cousins) and only $2 \%$ said they were alone.

\section{Discussion}

\section{PA during confinement}

Regular PA brings many benefits to the physical, mental and emotional health of the individual and is an essential component of a healthy lifestyle [27, 28]. According to the WHO, it is considered that to obtain the maximum benefits from physical activity, at least $150 \mathrm{~min} /$ week of moderate intensity PA or $75 \mathrm{~min} /$ week of vigorous intensity PA should be performed [20]. A high level of physical inactivity is observed worldwide, which in the Latin American case reaches 39\% [29]. According to the results of the consultation of this study, at least $73 \%$ of the respondents reported PA levels equal to or lower than 120 $\mathrm{min} /$ week, which reveals a high level of sedentary lifestyle in the group evaluated. However, it is possible to attribute the worsening of this trend to the quarantine situation to which the population has been forced, as has been reported in a recent study [30]. According to a previously published study, three aspects stand out: the first is that the practice of regular exercise is not deeply rooted in Panamanian society when compared to the rest of Latin America; secondly, the percentage of Panamanians who do not perform exercises or do any sport is around $61 \%$ and is double the average for Latin America; and thirdly, the PA that Panamanians do the most is playing soccer, walking and running [31]. Another factor that contributes to physical inactivity in the Panamanian society due to the quarantine situation to prevent the spread of COVID-19 is the decrease in incidental PA, which is related to the set of activities that the person performs in their life daily, such as going to work, regular shopping, walking the pet and that do not obey a particular structure [32]. This condition, which drastically reduces physical contact between people and decreases the movement of people [33, 34], also reduces incidental PA, which has beneficial effects on people's health since it keeps them active [32].

The positive and significant correlation found between the scores of the PIL test and the time dedicated to PA reported by the respondents (Tab. 2) can be explained, since when the person has a strong sense and purpose of life, it is generally a very active person who performs activities that lead to maintaining their health state. Hooker and Masters [35] found a positive association between the purpose of life, PA objectively measured with accelerometer (PA of moderate to vigorous intensity) and subjectively reported PA by a group of 104 women $(34 \pm$ 15 years). Holahan and Suzuki [36] found a positive association between life purpose and regular PA in a group of 162 elderly individuals ( $86 \pm 4$ years). The results of this study confirm the hypothesis that in general, people who have clear objectives and goals to achieve and feel good are more physically active. The significance tests to establish differences between the PIL test scores and the PA levels did not give significant differences, probably due to the high percentage of physical inactivity found in the follow-up sample.

\section{RM during confinement}

An interesting finding from this study is the positive and significant correlation between age and RM, and between PA and RM. This result could imply, for the sample of surveyed respondents, that the elderly have a certain degree of protection against stress due to the benefits of the regular practice of mental relaxation/meditation. In the same way, people who do RM regularly may try to do more PA. The association between PA and RM has been reported in another work, such as that of Strowger et al. [37], who conducted a national cross-sectional study in the United States on a sample of 34,425 individuals, and found that Americans who practiced mindfulness meditation were less likely to be inactive physically and more likely to comply with the PA recommendations, and also posed a hypothesis for future research to corroborate whether the intervention of mindfulness meditation - either as a complementary component or by itself - helps to increase or maintain PA.

The relationship between RM and stress reduction and feeling good about oneself has been reported in different studies $[38,39,40]$, and it is in line with the results obtained in this study where RM and PIL test values are positively correlated, as well as there is a higher value of the PIL test for those people who practice RM at least $30 \mathrm{~min} /$ week. In this sense, people who practice RM for less than $30 \mathrm{~min} /$ week have a PIL test score of $112 \pm 16$, which is significantly lower than in the case of those who practice RM for more than $30 \mathrm{~min} /$ week, whose PIL test score is $119 \pm 12$. The time spent performing RM probably leads to a decrease in stress and anxiety, and a greater feeling of well-being that translates into higher PIL test scores. This prompts researchers to propose meditation activities as a means of preventing and overcoming stress and frustration generated by prolonged confinement by COVID-19.

\section{Worry, happiness, sleep and number of people in con- finement}

The uncertainty about the economy, the loss of employment, being able to meet the payment of different obligations and aspects related to health and the possibility of contracting COVID-19 is what worries the citizens surveyed the most. This result is consistent with the opinion of some experts on the subject, who state that uncertainty is the factor that generates stress, especially due to possible economic losses and restrictions on personal freedom caused by the COVID-19 pandemic [41]. This situation of economic uncertainty is unprecedented for Panamanians, who for many years have enjoyed significant economic growth. By 2012, Panama had the highest growth rate, of even some developed countries, with unemployment rates for the formal sector of around 4\% [42]. This could explain why the main concern of Panamanians was to lose the economic well-being that they have enjoyed for many years.

The confinement situation causes, among other problems, sleep disorder and insomnia. In a study carried out in Italy to establish the effects of the COVID 19 pandemic, Di Renzo et al. [43] reported that $52.2 \%$ had difficulty sleeping. In another similar study in Italy, Gualano et al. [7] found that $42.2 \%$ had sleep disorders, and there were also symptoms of depression and anxiety; however, they also found that being married and being accompanied decreases the probability of having these conditions. In Panama, Matus et al. [44] found a high prevalence of perceived stress, especially in men; likewise, they also indicated that single people feel more stress and feel more alone than married people. According to the data collected in this research, the average NPC is $4 \pm 2$, and the affiliation of these people is usually a partner, children and siblings. Additionally, 
what makes Panamanians happier under these circumstances is being able to share with their family. These allow us to suggest the idea that being accompanied, instead of being a source of stress, allows people to feel accompanied to share, talk, play, making the time that seems to extend during the confinement situation not cause so much stress, anxiety and sleep problems.

\section{PIL}

The mean value of the PIL test $(113 \pm 16)$ is within the range reported in other studies, such as that of Gottfried [24] in inhabitants of five cities in Argentina (ages between 31-60 years, $112.89 \pm 16.34$; ages $21-30$ years, $107.76 \pm 16.40$ ); Reker and Cousins [25] in young Canadian university students (mean age 19.39 years, $105.46 \pm 13.48$ ); Halama [26] in young Slovak university students (average age $20.1 \pm 1.5$ years, $105.9 \pm 14.1$ ).

Different studies have found that older people also have higher PIL scores and, consequently, a strong sense of life purpose. In this study, the 20-30-year-old group had an average PIL test score of $108 \pm 17$ and it differs significantly from the groups that are over 30 years old that have average scores between $115 \pm$ 14 and $117 \pm 13$ (Fig. 3). This also explains the positive and significant correlation found between age and the PIL test. This trend between age and PIL test scores was reported by Gottfried [24] who, in the case of Argentina, found that the 21-30 group had an average of $107.8 \pm 16.4$ and for the 31-60 group years an average of $112.9 \pm 16.3$. Similar results are also found in other studies, such as Noblejas de la Flor [18] and Crumbaugh [17]. In the application of the PIL test to groups of young people, Reker and Cousins [25] reported $105.5 \pm 13.5$ (mean 19.5 years of age); in pre-university students, Moreno et al. [45] found a mean value of $103 \pm 17$, and Halama [26] noted a mean value of $105.9 \pm 14.1$ in university students $(20.1 \pm 1.5$ years $)$. It can be indicated that mature people, with more experience as a result of having lived longer, find greater meaning and purpose in life.

Taking into consideration the classification of the scores of the PIL test in the lack of meaning, area of uncertainty and presence of goals, in this research the highest proportion was located in the last line with $60 \%$, which seems reasonable since the average age of the respondents was $39 \pm 11$. This result is in accordance with that of Quintero de Acevedo [46], who worked with people of mature age, and the percentage of people who were located in the area with meaning and purpose in life was 79.8 and 76.5, for men and women, respectively. In the study carried out by Moreno et al. [45] in pre-university students, $77.2 \%$ were located in the zone of lack of meaning in life and in the zone of uncertainty. This behavior of the PIL test scores is related to age, as mentioned previously. However, in people with an average age of 77.9 years, Rodriguez [47] found that only $5 \%$ were in the zone of presence of goals and meaning of life. This could suggest that at extreme values of age, young and old, the test values tend to be lower.

When considering the effect of confinement on the mental health of people, it can be stated, in relation to what is indicated by the PIL test and at the time of application of the instrument, that no major consequences are observed in relation to the indicators that the survey evaluates.

\section{Conclusions}

Confinement for long periods of time produces an increase in sedentary lifestyle, since it decreases the level of PA, including incidental, which can generate a series of effects on health at the muscular, cardiovascular and endocrine levels, as suggested by some models of inactivity [48]. The low level of PA reported by those surveyed can be reversed through intervention plans aimed at people, so that they can stay active at home, while taking control of the pandemic. In a country like Panama, where sports practice and regular PA is not very common, especially in women, it should be a short-term objective to promote an increase in PA [49].

On the other hand, in addition to designing programs that help increase PA at home, stress generated during the confinement situation can be managed with properly directed mental relaxation/meditation activities, with methods used even in therapies against stress and anxiety. In this sense, regular practice of activities that combine physical activity with relaxation, such as yoga, has shown multiple health benefits [50]. In this work, it was found that mental relaxation leads to significant improvements, even in short periods of time, so its use as a tool to fight the effects of the coronavirus can be promoted. Practiced together, PA-RM can provide protection to the mental and physical health.

\section{References}

1. Cucinotta D., Vanelli M. (2020). WHO Declares COVID-19 a Pandemic. Acta Biomedica 91(1), 157-160.

2. Vaira L., Salzano G., Deiana G., Riu G. (2020). Anosmia and Ageusia: Common findings in COVID-19 patients. Laryngoscope 130(7), 1787. DOI: 10.1002/lary.28692

3. MINSA (2020). Press Release 1: Releases COVID-19. Retrieved August 26, 2020, from: http://minsa.b-cdn.net/sites/ default/files/general/comunicado_ndeg_l.pdf

4. MINSA (2020). Press Release 2: Releases COVID-19. Retrieved August 26, 2020, from: http://minsa.b-cdn.net/sites/ default/files/general/comunicado_ndeg_2.pdf

5. Adhanom T. (2020). WHO Director-General's opening remarks at the media briefing on COVID-19 - 11 March 2020, World Health Organization. Retrieved August 5, 2020, from: https://www.who.int/es/dg/speeches/detail/who-director-general-s-opening-remarks-at-the-media-briefingon-covid-19---11-march-2020

6. Cellini N., Canale N., Moini G., Costa S. (2020). Changes in sleep pattern, sense of time and digital media use during COVID-19 lockdown in Italy. Journal of Sleep Research 29(4). DOI: 10.1111/jsr.13074

7. Gualano M.R., Lo Moro G., Voglino G., Bert F., Siliquin R. (2020). Effects of Covid-19 lockdown on mental health and sleep disturbances in Italy. International Journal of Environmental Research and Public Health 17(13), 4779. DOI: 10.3390/ijerphl7134779

8. Nicola M., Alsafi Z., Sohrabi C., Kerwan A., Al-Jabir A. et al. (2020). The socio-economic implications of the coronavirus pandemic (COVID-19): A review. International Journal of Surgery 78, 185-193. DOI: 10.1016/j.ijsu.2020.04.018

9. Biddle S.J. (2018). Physical activity and mental health in young people. In: 2nd Yogyakarta International Seminar on Health, Physical Education, and Sport Science (YISHPESS 2018) and lst Conference on Interdisciplinary Approach in Sports (CoIS 2018), 278, 366-368. Atlantis Press.

10. Rimmele U., Seiler R., Marti B., Wirtz P. H., Ehlert U., Heinrichs M. (2009). The level of physical activity affects adrenal and cardiovascular reactivity to psychosocial stress. Psychoneuroendocrinology 34(2), 190-198. DOI: 10.1016/j. psyneuen.2008.08.023

11. Wijndaele K., Matton L., Duvigneaud N., Lefevre J., De Bourdeaudhuij I. et al. (2007). Association between leisure time physical activity and stress, social support and coping: 
A cluster-analytical approach. Psychology of Sport and Exercise 8(4), 425-440. DOI: 10.1016/j.psychsport.2006.08.001

12. Astin J.A. (1997). Stress Reduction through Mindfulness Meditation: Effects on psychological symptomatology, sense of control, and spiritual experiences. Psychotherapy and Psychosomatics 66(2), 97-106. DOI: 10.1159/000289116

13. Rausch S.M., Gramling S.E., Auerbach S.M. (2006). Effects of a single session of large-group meditation and progressive muscle relaxation training on stress reduction, reactivity, and recovery. International Journal of Stress Management 13(3), 273-290. DOI: 10.1037/1072-5245.13.3.273

14. Coppola F., Spector D. (2009). Natural stress relief meditation as a tool for reducing anxiety and increasing self-actualization. Social Behavior and Personality: an International Journal 37(3), 307-311. DOI: 10.2224/sbp.2009.37.3.307

15. Yanyu J., Xi Y., Huiqi T., Bangjiang F., Bin L. et al. (2020). Meditation-based interventions might be helpful for coping with the coronavirus disease 2019 (COVID-19). OSF Preprints, DOI: 10.31219/osf.io/f3xzq

16. Crumbaugh J.C., Maholick L.T. (1964). An experimental study in existentialism: The psychometric approach to Frankl's concept of noogenic neurosis. Journal of Clinical Psychology 20, 200-207.

17. Crumbaugh J.C. (1968). Cross-validation of Purpose-In-Life test based on Frankl's concepts. Psychology 24(1), 74-81.

18. Noblejas de la Flor M.D. (1994). Logotherapy. Fundamentals, Principles and Application. An evaluation experience of the „inner achievement of meaning”. Doctoral dissertation, Universidad Complutense de Madrid, Madrid. [in Spanish]

19. Hernández R., Fernández C., Baptista P. (2010). Metodología de la Investigación. México: Mc Graw Hill.

20. World Health Organization (2010). Global recommendations on physical activity for health. Retrieved January 4, 2020, from: https://apps.who.int/iris/bitstream/handle/10665/44399/9789241599979_eng.pdf?s

21. Kabat-Zinn J. (1990). Full catastrophe living: Using the wisdom of your body and mind to face stress, pain, and illness. New York: Delacorte.

22. Hirshkowitz M., Whiton K., Albert S. M., Alessi C., Bruni O. et al. (2015). National Sleep Foundation's sleep time duration recommendations: methodology and results summary. Sleep Health 1, 40-43. DOI: 10.1016/j.sleh.2014.12.010

23. Watson N.F., Badr M.S., Belenky G., Bliwise D.L., Buxton O.M. et al. (2015). Recommended amount of sleep for a healthy adult: A joint consensus statement of the American Academy of Sleep Medicine and Sleep Research Society. Sleep 38(6), 843-844. DOI: 10.5665/sleep.4716

24. Gottfried A.E. (2016). Argentine adaptation of the PIL Test (Test of Meaning in Life) by Crumbaugh and Maholick. Revista de Psicología 12(23), 49-65. [in Spanish]

25. Reker G.T., Cousins J.B. (1975). Factor structure, construct validity and reliability of the Seeking of Noetic Goals (SONG) and Purpose in Life (PIL) Test. Journal of Clinical Psychology 35(1), 85-91. DOI: 10.1002/1097-4679(197901)35:1<85::AID-JCLP2270350110>3.0.CO;2-R

26. Halama P. (2009). The PIL test in a Slovak sample: internal consistency and factor structure. The International Forum for Logotherapy 32, 84-88.

27. Donnelly J., Hillman C., Castelli D., Etnier J., Lee S. et al. (2016). Physical activity, fitness, cognitive function, and academic achievement in children. A systematic review. Medicine Science in Sports Exercise 48(6), 1197-1222. DOI: 10.1249/MSS.0000000000000901
28. Długołęcka B., Jówko E., Czeczelewski J., Cieślinski I., Klusiewicz A. (2019). Bone mineral status of young men with different levels of physical activity. Polish Journal of Sport and Tourism 26(1), 8-13. DOI: 10.2478/pjst-2019-0002

29. Guthold R., Stevens G.A., Riley L.M., Bull F.C. (2018). Worldwide trends in insufficient physical activity from 2001 to 2016: a pooled analysis of 358 population-based surveys with 1.9 million participants. Lancet Glob Health 6, el077-el086. DOI: 10.1016/S2214-109X(18)30357-7

30. Ammar A., Brach M., Trabelsi K., Chtourou H., Boukhris O. et al. (2020). Effects of COVID-19 home confinement on eating behaviour and physical activity: Results of the ECLB-COVID19 international online survey. Nutrients 12(6), 1-13. DOI: $10.3390 /$ nul2061583

31. Dichter Neira Research Network (2015). The practice of sports in Panama. Retrieved August 18, 2020, from: //www. dichter-neira.com/wp-content/uploads/2016/02/La-pr\%C3\%Alctica-de-deportes-en-Panam\%C3\%Al_-septiembre2015-Versi\%C3\%B3n-Final-2-4.pdf [in Spanish]

32. Sanchez-Lopez J., Silva-Pereyra J., Fernández T., Alatorre Cruz G.C., Castro-Chavira S.A. et al. (2018). High levels of incidental physical activity are positively associated with cognition and EEG activity in aging. PLoS ONE 13(1). DOI: 10.1371/journal. pone.0191561

33. Gensini G.F., Magdi H., Yacoub M.H., Conti A.A. (2004). The concept of quarantine in history: from plague to SARS. Journal of Infection 49(4), 257-261. DOI: 10.1016/j. jinf.2004.03.002

34. Schabas R. (2019). Is the quarantine act relevant? Canadian Medical Association Journal 176(13), 1840-1842. DOI: 10.1503./cmaj.070130

35. Hooker S.A., Masters K.S. (2014). Purpose in life is associated with physical activity measured by accelerometer. Journal of Health Psychology 21(6), 962-71. DOI: $10.1177 / 1359105314542822$

36. Holahan C.K., Suzuki R. (2006). Motivational factors in health promoting behavior in later aging. Activities, Adaptation Aging 30(1), 47-60. DOI: 10.1300/J016v30n01_03

37. Strowger M., Kiken L.G., Ramcharran K. (2018). Mindfulness meditation and physical activity: Evidence from 2012 National Health Interview Survey. Health Psychology 37(10), 924-928. DOI: 10.1037/hea0000656

38. Manzoni G.M., Pagnini F., Castelnuovo G., Molinari E. (2008). Relaxation training for anxiety: a ten-years systematic review with meta-analysis. BMC Psychiatry 8(41). DOI: 10.1186/1471-244X-8-41

39. Park E.R., Traeger L., Vranceanu A.M., Scult M., Lerner J.A. et al. (2013). The development of a patient-centered program based on the relaxation response: The Relaxation Response Resiliency Program (3RP). Psychosomatics 54(2), 165-174. DOI: 10.1016/j.psym.2012.09.001

40. Shapiro S.L., Jazaieri H., de Sousa S. (2016). Meditation and positive psychology. In: C. Snyder, S.J. Lopez, L.M. Edwards, S.C. Marques (eds.), The Oxford Handbook of Positive Psychology (pp. 1-30). Oxford Handbooks Online.

41. Pfefferbaum B., North C.S. (2020). Mental health and the Covid-19 pandemic. The New England Journal of Medicine 383, 510-512. DOI: 10.1056/NEJMp2008017

42. Brown H., Luna C.I. (2013). Panama: economic growth at the expense of politics. Revista de Ciencia Política (Santiago) 33(1), 287-301. DOI: 10.4067/S0718-090X2013000100014

43. Di Renzo L., Gualtieri P., Cinelli G., Bigioni G., Soldat L. et al. (2020). Psychological aspects and eating habits during COVID-19 home confinement: Results of EHLC-COVID-19 
Italian Online Survey. Nutrients 12(7), 2152. DOI: 10.3390/ nul2072152

44. Matus E., Matus L., Florez A.M., Stanziola M., Araguás N. et al. (2020). Stress in Panama due to COVID-19. Retrieved August 30, 2020, from: https://www.researchgate.net/publication/343294796_ESTRES_EN_PANAMA_POR_COVID-19_Publicado [in Spanish]

45. Moreno V., Risco Lázaro A., Sánchez Cabaco A., Urchaga Litago J.D. (2010). Sense of life: empirical study in secondary school students. Paideia 48. Retrieved August 10, 2020, from: https://revistas.udec.cl/index.php/paideia/article/ view/1783 [in Spanish]

46. Quintero de Acevedo O. (2015). Sense of life, anxiety and depression in mature women. Doctoral dissertation, Universidad Autónoma de Madrid, Madrid. Retrieved August 10, 2020, from: https://repositorio.uam.es/bitstream/handle/10486/669527/quintero_de_acevedo_olga.pdf?seq [in Spanish]

47. Rodríguez D. (2016). Relationships between the meaning of life, physical activity, the social support network, gender and age in adults over 7 day centers in the province of Heredia. Doctoral dissertation, Universidad Nacional, Heredia. [in Spanish]

48. Narici M., De Vito G., Franchi M., Paoli A., Moro T. et al. (2020). Impact of sedentarism due to the COVID-19 home confinement on neuromuscular, cardiovascular and metabolic health: Physiological and pathophysiological implications and recommendations for physical and nutritional countermeasures. European Journal of Sport Science 21(4). DOI: $10.1080 / 17461391.2020 .1761076$

49. Nowak M. (2008). Impact of recognized by women health and physical-fitness-related values on the length of their physical activity. Polish Journal of Sport and Tourism 15(4), 174-183.

50. Grabara M. (2017). Hatha yoga as a form of physical activity in the context of lifestyle disease prevention. Polish Journal of Sport and Tourism 24(2), 65-78.

Submitted: June 22, 2021

Accepted: June 29, 2021 